\title{
La vUlgarización dE LAS CIENCIAS, ESPACIO DE CRÍTICA DEL CIENTIFICISMO ${ }^{1}$
}

\author{
DANIEL RAICHVARG ${ }^{2}$
}

\section{Resumen}

La vulgarización de las ciencias como práctica cultural no escapa a los riesgos en que puede incurrir toda presentación pública de las ciencias, sea formal o informal. Uno de estos riesgos es el de seguir alimentando una idea de la ciencia como discurso aparte, separado de la sociedad o al menos situado por encima de los debates públicos y de la producción cultural ordinaria. El autor muestra, mediante varios ejemplos, cómo las prácticas de vulgarización científica de todo tipo pueden servir como escenarios de crítica de los mitos modernos y contemporáneos de la ciencia. Examina en particular algunas de las figuras del cientificismo moderno en los cortocircuitos de pensamiento que se forman cuando la ciencia deviene práctica cultural corriente a partir de las producciones y objetos artísticos y culturales, incluso los más triviales.

1 Este artículo fue elaborado por Daniel Raichvarg a partir de un seminario que dictó en la Universidad Nacional de Colombia, sede Medellín, en agosto de 2005. Se publica con autorización del autor. Traducido del francés por Jorge Márquez Valderrama (profesor asociado del Departamento de Estudios Filosóficos y Culturales de la Facultad de Ciencias Humanas y Económicas de la Universidad Nacional de Colombia, sede Medellín).

2 Profesor de la Universidad de Borgoña en Ciencias de la Información y de la Comunicación. Director del Laboratorio CIMEOS (Communications, MEdiations, Organisations, Savoirs). Vicepresidente delegado en Cultures et Cités de la misma universidad. 


\section{Palabras clave}

Vulgarización de la ciencia, Crítica al cientificismo, Difusión del saber, Difusión de la ciencia.

\section{Abstract}

Sciences vulgarization like a cultural practice does not escape to the risks which all public sciences presentation can incur, is formal or informal. One of these risks is to continue feeding an science idea like separate speech, separated of the society or at least located over the debates public and on the ordinary cultural production. The author shows, by means of several examples, how all kind of scientific practices vulgarization can serve like critic modern scenes and contemporary myths as science. It in particular examines some of the modern figures Scientificism in the thought short circuits that form when science happens current cultural practice from the productions and artistic and cultural objects, even most trivial.

\section{Key words}

Science vulgarization, Critic to the Scientificism, Knowledge diffusion, Science diffusion. 
El título habla más de una tesis que de una afirmación o de una certidumbre, pero esa tesis merece ser lanzada.

\section{Atributos de una concepción-Pantalla DE LA VULGARIZACIÓN DE LAS CIENCIAS}

Cuando se examina la manera como se habla de las "posturas de la vulgarización científica", parece claro que, sin que haya necesidad de hacer un análisis lexicográfico, las palabras y expresiones "saberes", "conocimientos", "difusión de los conocimientos", incluso "transferencia de conocimientos", "distribución de los conocimientos"... están presentes en los textos de forma abundante, sin importar su proveniencia: opiniones de científicos, reportes de orígenes diversos, puntos de vista de vulgarizadores o de activistas de ese campo. Ese enfoque ha sido incluso dominante a lo largo de varios siglos. Tres citas que podrían provenir de escritos contemporáneos, aunque dos de ellas salen textuales de finales del siglo XIX y la otra de mediados del siglo XX. Tres citas que contextualizamos, pero que no requieren análisis particular porque son legibles directamente como portadoras de tres atributos de la concepción-pantalla que comenzamos a esbozar:

1. Si la vulgarización de las ciencias anda mal, es porque el mensaje es mal transmitido o mal hecho.

2. Quienes no poseen el saber no son los más idóneos para vulgarizarlo.

3. Toda discusión que cuestione los dos primeros atributos no puede sostenerse...

La primera cita proviene del prefacio del libro Les étapes de la science (1892). El autor, Émile Gauthier, fue un gran vulgarizador del siglo XIX, sucesor del fundador y director de L'année scientifique, Louis Figuier ${ }^{3}$, mucho más famoso que el primero. El prefacio fue

\footnotetext{
Señalemos, incluso si no parece importante, que Émile Gauthier era un antiguo comunero que había regresado algunos años atrás de Cayenne. Sucedió a Louis Figuier cuando éste murió.
} 
redactado por Mr. Jean-Louis de Lanessan, profesor de ciencias naturales y médicas en el Museo de Historia Natural, amigo de Paul Bert y, como él, diputado republicano, darwinista, anticlerical declarado, autor de artículos para el Larousse Universel y redactor de las leyes Jules Ferry, particularmente la parte concerniente a la enseñanza de las ciencias en la Escuela.

"Nuestra vulgarización de la ciencia está lejos de producir todos los resultados que se estaría autorizado a esperar de ella y hay más esfuerzos producidos que efecto útil obtenido. Artículos de revistas, folletines y crónicas de periódicos son dejados de lado con mucha frecuencia porque no son comprendidos lo suficiente. Convendría dedicarse a una historia de la difusión de las ciencias. Muchos hechos curiosos, ciertas consideraciones interesantes encontrarían lugar en un trabajo de ese tipo"”.

La segunda cita también proviene de un para-texto, aunque de un tipo particular: la carta de un científico a su... mamá. En esta carta a su madre ${ }^{5}$, de febrero de 1889, el pasteriano Alexandre Yersin, descubridor del bacilo de la peste, se queja (teniendo como fondo la Torre Eiffel en plena construcción) de las bufonerías de los aduaneros, de la mantequilla y de las medias, de los periodistas que, cuando "se entrometen en ciencia, sólo dicen tonterías".

Querida mamá:

Recibí tu carta, la mantequilla y las medias remendadas, pero este último paquete ya no tenía atadura y el papel estaba desecho. Los aduaneros son muy sospechosos por estos tiempos.

El artículo de L'Estafette sobre la rabia no se sostiene. El pretendido descubrimiento ruso data de hace más de un año y hay fuertes razones para considerarlo inexacto. Además, si fuera cierto, el descubrimiento no tiene nada que ver con las vacunaciones contra la rabia.

4 Para un pequeño guiño ad hominen, véase: RAICHVARG D., JACQUES J. (1991), Savants et ignorants, une histoire de la vulgarisation des sciences, Paris, Seuil, col. Science ouverte (nouvelle édition: Collection Points Ciencias, 2003).

5 Una copia de esta carta me ha llegado por la vía de Mr. Henri MOLLARET, pasteriano actual, ya fallecido, y autor de varios trabajos sobre Yersin, para cuya elaboración había tenido acceso a los archivos personales de Yersin. 
Cuando los periodistas se entrometen en ciencia, sólo dicen tonterías. Así, esta semana Le Figaro aseguró que habíamos encontrado la vacuna contra la difteria. Ese artículo nos valió una avalancha de reporteros de todos los periódicos de París, que querían más detalles. Recibí a dos de ellos, el de Le Matin y el de La Liberté. Simplemente les entregué copia de nuestro artículo diciéndoles que allí encontrarían todos los detalles posibles. ¡Lo que no impidió al reportero de Le Matin, escribir en el periódico del día siguiente, que yo le había dicho que las vacunaciones contra la difteria estaban casi listas y que nosotros ya vacunábamos a los animales! Luego de todo eso, le encargué al conserje de decirles a todos los que vinieron después que fueran a fijarse si yo estaba en la calle de Ulm.

Creo que harías bien en renunciar completamente al yoduro que te causa tantas molestias.

En esta semana hemos tenido un tiempo espantoso: lluvia, viento, nieve; en cambio hoy no hay ni una nube y hace un frío muy fuerte. La torre Eiffel está casi terminada. Puedo seguir desde mi habitación los progresos de su construcción. Definitivamente, es algo digno de ser visto.

Adiós querida mamá, dos fuertes besos de tu hijo afectuoso.

Dr. Yersin

París, 10 de febrero de 1889

¿Sólo sirve para eso la vulgarización? ¿Será que la única manera de pensarla, de evaluarla es según los conocimientos transmitidos? ¿Los discursos que se puede sostener sobre ella son sólo los que intentan esclarecer por medio de La Luz, de Las Luces, o sea, "LA CIENCIA"? En resumen, ¿la vulgarización de las ciencias sería solamente la expresión suprema del cientificismo contemporáneo, cuando no eterno? ¿No podemos soñar otra cosa para ella?

Hace más o menos 45 años, el filósofo de las ciencias Georges Canguilhem ${ }^{6}$ intentó una ruptura en torno al modelo difusionista

6 Canguilhem G. (1961). Nécessité de la diffusion scientifique, Revue de l'enseignement supérieur, 3. 
de la vulgarización de las ciencias: los laboratorios producen conocimientos y estos últimos, al salir del laboratorio, necesariamente, no pueden más que perder conocimiento (isic!, diría Lacan). A partir de esta concepción, Canguilhem concebía incluso "una especie de casuística en deontología científica: ¿en qué casos y para qué fines legítimos una pérdida de saber por difusión del saber merece ser aceptada?". Leamos la argumentación completa:

Se concibe entonces que aquí y allá (queremos decir fuera de Francia), la vulgarización de la ciencia pueda aparecer como una parte de la tarea colectiva de los científicos, en las Academias y en las Universidades. No es que las objeciones no sean numerosas. Incluso podrían ser hoy más fuertes que nunca [...].

[...] La concepción moderna de la información y de la transmisión de información renueva un problema que la preexistía. La difusión de las ciencias se presenta como un caso extraordinario de aplicación de las leyes relativas a la cantidad de información y a la probabilidad de una disminución de información debida a su transmisión [...] Al asimilar un saber original rigurosamente estructurado al estado altamente improbable de un sistema físico, y el mismo saber difundido - cuyos transmisión, recepción y uso han alterado la coherencia inicial-a un sistema cuya entropía ha aumentado, se puede concebir una especie de casuística en deontología científica: ¿en qué casos y para cuáles fines legítimos una pérdida de saber por difusión del saber va a ser aceptada?

Si la difusión del saber se salda por una pérdida de energía, ¿qué deber asigna la constatación de este hecho a la ciencia y a la sociedad? Ese deber consiste en reducir al mínimo esa pérdida de energía mediante un control científico de la difusión de la ciencia, sea porque los científicos mismos confieran más interés y atención a una empresa que no todos desprecian, sea porque la Universidad asuma indirectamente la gestión de una institución para-universitaria de difusión y de vulgarización bajo todas sus formas, y en varios grados, de la difusión ilustrada a la difusión popular. El objetivo por alcanzar es ante todo el de conservarle a la ciencia en vías de difusión lo esencial de sus estructuras formales, por fuera de lo cual lo que es difundido bajo el nombre de ciencias se les asemeja en tan 
escasa medida como el juego del columpio se parece a la teoría del péndulo compuesto. Luego el objetivo es introducir explícitamente en la vulgarización la indicación de sus límites, sin poner separaciones entre la vulgarización de los resultados y la vulgarización de los métodos, de las controversias, acompañada de un recuento histórico de las investigaciones. En resumen, de nuevo es a los científicos a quienes hay que recurrir para evaluar la vulgarización de las ciencias, para defender a su antojo su capilla.

Segunda figura cientificista: después de una vulgarización de las ciencias que sólo sería difusión de los conocimientos..., una vulgarización de las ciencias que sería propiedad exclusiva de la comunidad científica. ¡La apertura de Canguilhem tiene sus límites!

Se puede lamentar que Canguilhem y muchos otros no cuestionen directamente el modelo ampliamente dominante que organiza, estructura -negativamente- al mismo tiempo las acciones y las investigaciones en la materia: el postulado de la independencia y de la anterioridad de la producción científica con respecto a la actividad de comunicación y de divulgación (de ahí el "top-down and dissemination-oriented model" de los anglosajones), con la consecuencia de concebir a esta última como una fatal degradación del mensaje circulante, en términos de pérdidas, el "deficit model" También se podría lamentar que todo intento de discusión de ese modelo se vea contaminado por una voluntad de hacer daño a la ciencia (tercera figura de la concepción-pantalla). Entonces hay que tomar una decisión: como no se discute ese modelo, ya no se busca discutirlo, se lo dialectiza y se ve a dónde nos lleva eso. El axioma "la vulgarización científica es difusión de conocimientos", debe ser dialectizado. ${ }^{8}$ Es innegable que la vulgarización científica es eso, pero es algo más. Dialectizado ese axioma, como diría Gaston Bachelard, hace cantar todos los programas de investigación.

7 Irwin, A. \& Wynne, B. (1996). Misunderstanding science? The public reconstruction of science and technology. Cambridge, University Press.

8 Bachelard G. (1962). La Philosophie du Non. Paris: Presses Universitaires de France. 


\section{La VUlgaRización dE LAS CIENCIAS COMO DISTANCIAMIENTO CRÍtICO}

Trabajaremos el concepto de "vulgarización de las ciencias", y lo haremos variar en su extensión y en su comprensión -según la expresión de Georges Canguilhem-, mediante dos enfoques.

Un enfoque teórico-práctico propuesto en textos de reflexión, pero enunciado en el momento de acciones de vulgarización y no "en frío".

Una aproximación por la vía de los objetos que definiremos como "populares-médiaticos", en lo que tienen de populares -en lo bajo de la escala: de la tarjeta postal a la canción precisamente popular, del documental a la obra de teatro-y en lo que tienen de mediáticos, pues instauran una relación de mediación entre las ciencias y las técnicas (las tecnociencias) y las personas, el pueblo (no eludamos las grandes palabras.... ${ }^{10}$.

El primer enfoque conduce a una vulgarización concebida como pensamiento crítico del cientificismo; el segundo, a una vulgarización concebida como práctica crítica del cientificismo.

9 Bélisle, C., Bianchi, J., Jourdan, J. (1999). Pratiques médiatiques. 50 mots-clés. Paris : CNRS Éditions, p. 77-83.

10 Estas investigaciones llevadas a cabo en el laboratorio CIMEOS (EA 4177, Université de Bourgogne) cubren un amplio campo de trabajos: sobre las imágenes de las ciencias y de las técnicas en las culturas; sobre las relaciones entre saberes y prácticas cotidianas en las culturas; sobre las relaciones con los saberes de las diferentes actores, sobre la concepción y la evaluación de contenidos y de modalidades de difusión, comprendida la multiplicidad de las culturas. Varias tesis se han sustentado y varios libros se han publicado al respecto: KERZANET, M., Le théâtre pour la ciencia, la ciencia par le théâtre, Université de Bourgogne, Centre de Recherche sur la Culture et les Musées, soutenue le 11 mars 2002 (publiée en ouvrage sous le titre : Le théâtre de ciencias, CNRS éditions, 2006) et BERTRAND. J.-M., 2001 : Odyssée de l'espace, puissance de l'énigme, soutenue le 26 novembre 2003 (publiée en ouvrage, édition L'Harmattan, collection Champs visuels, 2006), UEBERSCHLAG J. (2007). Jean Brérault (1898-1973), l'instituteur cinéaste. Presses Universitaires de St Etienne. 


\subsection{La vulgarización, pensamiento crítico del cientificismo}

Las críticas sobre las formas que la vulgarización ha adoptado, las críticas "al estilo Lanessan", conforman legiones. Desde hace mucho tiempo, las revistas de vulgarización de las ciencias, las páginas y los folletines científicos de los grandes cotidianos políticos, contienen todos, rúbricas donde se discute, donde se debate acerca de la calidad de las producciones ${ }^{11}$. Sin embargo, detrás de esa crítica puramente formal, se perfila otra forma de crítica: ¿Estaría la vulgarización en condiciones de garantizar la legitimidad misma de la ciencia? En caso de respuesta afirmativa, ¿qué tipo de legitimidad? La ciencia legitimada (¡o no!) desde el exterior: ¡he ahí una proposición no cientificista! Cuatro siglos, cuatro ejemplos. Vamos a ver, en particular, que esa proposición, esa legitimación, en ningún caso tiene que ver con algún sentimiento anti-ciencia...

\section{8 - la vulgarización y el espacio público}

El primer ejemplo es extraído de la introducción al Rapport Général de l'Exposition Universelle de 1889. Como es frecuente en ese tipo de publicaciones, el autor hace una breve reseña histórica de las Exposiciones Universales. "Durante el siglo XVIII, el concurso anual de la Academia de pintura y de escultura dio lugar a memorias críticas muy numerosas entre las cuales algunas emanaban de escritores cultivados, como Diderot; y también dio lugar a panfletos, en verso o en prosa, que afectaban de una forma a veces seria, a veces bufona."

$\mathrm{El}$ autor se inscribe, pues, deliberadamente, en una comparación con las Exposiciones de Bellas artes, luego con los famosos Salones. Esto para recordarnos la función de crítica clásica, la crítica de pura forma. Luego precisa que, si bien antes de 1793,

11 Merrien-Duval, N. (2000). Les discours sur le livre científico pour enfants. Thèse de doctorat de l'Université Paris 11, soutenue le 8 septembre 2000 (direction : Daniel Raichvarg). 
“[...] esa Exposición de Bellas Artes sólo había sido abierta para los trabajos de algunos artistas eminentes, que consentían en mostrar estatuas, cuadros, grabados, encargados previamente con destinación especial..., a partir de 1793, todos los artistas tuvieron acceso al concurso y fueron admitidos para que probaran suerte. Esa modificación tuvo la ventaja de estimular y de poner de relieve talentos desconocidos". Dicho de otra manera, hubo sumisión a la crítica popular para validación de los mejores. Ya no le corresponde a un "augusto areópago" decidir sobre el valor de una obra, sino al gran público. Y es en ese marco conceptual de crítica de los avances de las técnicas que, como lo anota luego el autor de ese Reporte, el ministro del Interior François de Neufchâteau concibe, en 1798, la idea de una "exposición pública anual de los productos de la industria". Se trata entonces de ofrecer a los ciudadanos un espacio público de discusión sobre los valores de los avances de la técnica ${ }^{12}$.

\section{8 - La vulgarización, espacio de discusión}

El segundo ejemplo se halla en el folletín científico de la edición del 30 de julio de 1878 del periódico democrático La République Française. En ese momento se desarrolla la primera Exposición de Antropología, ciencia nueva, si eso existe en esa época. Aunque no hay firma de autor, es muy probable que se trate del científico y diputado Paul Bert, siempre interesado especialmente en los problemas de difusión de las ciencias. He aquí lo que escribe el encargado de ese folletín científico: "Se puede confesar ahora que el éxito coronó los esfuerzos de sus organizadores, la exposición

12 Prefiero poner en nota al pie la observación que sigue, porque hay que cuidarse de comparar de manera tan diacrónica que se corra el riesgo de caer en el anacronismo: sin embargo, anotemos que podemos cruzar el concepto de "espacio público", (demasiado) frecuentemente utilizado por los especialistas de de las relaciones ciencias-sociedades y la práctica de las conferencias ciudadanas, o también evocar la práctica de los Robins des Toits (asociaciones creadas en Francia para la defensa de la seguridad sanitaria en el consumo de tecnologías inalámbricas, n. del t.) o de los anti-transgénicos... 
de Antropología, esa exhibición de una ciencia demasiado alta y demasiado nueva, por haber recién entrado en la enseñanza clásica, esa exhibición era una audacia." Esto en cuanto a las tendencias exhibicionistas del mundo científico. Pero examinemos lo que sigue: "Hay otro punto de vista, quizás más importante, que debemos desarrollar, sobre todo en este lugar. La antropología es una ciencia en pleno avance, cuyas investigaciones de gabinete no son suficientes. Sus materiales de estudio están dispersos por todo el globo. La Exposición Universal era una ocasión única para someter a control y a discusión los materiales recogidos y darles una publicidad necesaria".

"Someter a control y a discusión los materiales recogidos". Una manera precisa de decir las cosas. ¡Democracia, democracia! La vulgarización hace parte del proceso mismo de las ciencias ${ }^{13}$ : la vulgarización no deja tranquila a la ciencia, no la deja sola frente a sí misma. Bella figura anticientificista.

\section{1 - La vulgarización como vigilancia social y epistemo- crítica}

La tercera proposición también proviene de un científico. Es evidente la importancia de captar el lugar de las diversas figuras de la vulgarización en ese momento: los científicos mismos las identifican y les dan relevancia. ${ }^{14} \mathrm{Un}$ autor como Jean-Marc LévyLeblond, de la misma manera que Paul Bert, con diversos trajes (el del científico-teórico, el del epistemólogo-crítico, el del vulgarizador, el del editor de colecciones de vulgarización ${ }^{15}$ ) y también encargado de un programa político sobre cultura científica, como el programa movilizador para la cultura científica de los primeros siete años del gobierno Mittérand, en 1981. Y fue precisamente en ese año, en el

13 De nuevo, sin caer en el anacronismo, se puede evocar la teoría del continuum (Abraham MOLES) y la dificultad contemporánea de aceptar o, simplemente, de discutir avances recientes de las tecnociencias desde el estricto punto de vista de los saberes en juego.

14 Devons-nous rajouter: "Et non des moindres"? En tout cas, des bien connus...

15 Collection Ciencia ouverte, éditions du Seuil. 
órgano de la Asociación Francesa de Escritores Científicos, cuando hizo un análisis en el cual añadía otro aspecto a las proposiciones de François de Neufchâteau y de Paul Bert:

No basta con que algunos heraldos de buena voluntad salgan de su torre de marfil a proclamar la buena nueva. También es necesario que algunos exploradores y algunos excavadores salidos del buen pueblo penetren allí para actualizar lo que los amos de los lugares no pueden o no quieren mostrar. Un papel indispensable les corresponde entonces a autores profanos, periodistas, por ejemplo, y no necesariamente especializados en la información científica, muy al contrario. Sólo ellos pueden tener la audacia de la ignorancia y el vigor necesario para exigir de los científicos que sea llevado al extremo el imposible e indispensable trabajo de elucidación y de vulgarización en el mejor sentido del término. La ciencia debe ser, como la política o la justicia, objeto de encuestas públicas apretadas y sin compromiso con la deferencia que ella inspira ${ }^{16}$.

Retengamos dos expresiones fuertes: "audacia de la ignorancia y vigor necesario", "trabajo de elucidación y de vulgarización en el mejor sentido del término"... Jean-Marc Lévy-Leblond empuja a abrir la puerta a la ignorancia, frente a una vulgarización que estaría centrada (incluso obsesionada) por su relación con los conocimientos. Él les reconoce a los periodistas, en particular, una función, cuando no nueva, al menos fuerte, incluso si, y quizás sobre todo, si ellos no provienen del serrallo de la ciencia. Y esos periodistas deben adelantar un trabajo de elucidación... Es decir, que les corresponde descubrir "cosas" que los científicos mismos, inmersos en sus probetas y con la mirada limitada por los baldosines blancos, no pueden percibir. Y esto en todos los sentidos del término, no solamente en momentos de acontecimientos tan singulares como el "el escándalo de la sangre contaminada", puesto en evidencia por una periodista, sino también con ocasión de reflexiones sobre

16 Lévy-Leblond, J.M. (1981). Bulletin d'Information de l'A.E.S.F. October 1981, 30, p. 14. 
asuntos internos de la ciencia ${ }^{17}$. La vulgarización vista entonces en acción en un doble trabajo de vigilancia: una vigilancia social, en la herencia de un Paul Bert, y una vigilancia epistemológica ${ }^{18}$.

\section{0 - La vulgarización como debate crítico}

Pero ¿qué piensan de todo eso los "heraldos", los periodistas? Ellos inaugurarán otra figura, una figura doblemente crítica, al abrir la discusión, precisamente, sobre la vulgarización. "Investigadores y periodistas: ¿no está fresco mi pescado?”, tal es la opción de Patrice Lannoy, antiguo presidente de la Asociación de Periodistas Científicos de la prensa de información, para el título del artículo qua aparece algún tiempo después de un coloquio cuya problemática complementa el paisaje del debate ${ }^{19}$ : ¿Quién manipula a quién?” No solamente la cuestión de la actualidad y de su cortejo plantea diferentes problemas; el de su validación académica, por el lado de las ciencias; el del sensacionalismo, por el lado de la prensa; sino además, los actores mismos pueden no estar muy "frescos". Algunos extractos de contribuciones de esos actores muestran la complejidad del asunto.

\section{Juegos y apuestas de saberes}

Algunos científicos interesados en hacer carrera, en la influencia, el reconocimiento, el éxito, han comprendido que los periodistas (también frágiles y humanos) adoran el pescado fresco... A saber, un descubrimiento científico todavía no publicado. Una exclusividad, o al menos, una información preferencial. Pero ¿en qué condiciones se efectúa la venta o la compra del pescado? Y he

17 Todavía hay recuerdos de Anne-Marie Casteret de L'Évènement, cuando evocaba los primeros elementos de lo que se convertiría en el debate de la sangre contaminada. Sin embargo, rápidamente, los defensores cientificistas de la ciencia dirán: "Eso no tiene que ver con la ciencia sino con las aplicaciones de la ciencia...”

18 La microbiología naciente es un buen ejemplo de función epistemocrítica de la vulgarización (RAICHVARG, D. (1995). Mots contre Maux, Essai sur la Microbiomanie scientifique et vulgaire. Alliage. 22, 32-38).

19 Coloquio organizado en 1995 por la AJSPI en la Ciudad de las ciencias y de la Industria de París. 
aquí... La idea de una información correcta en todos sus aspectos, es decir desprovista de subjetividad, sigue siendo aquí, en pleno campo científico, una pobre ilusión. ¿Es la “misión” de los medios difundir el saber? Sin entrar en otro debate, es claro que hay una fuerte confusión entre los dos temas que afronta el periodista que debe trabajar en esos dominios. Claro está, el periodista debe preocuparse por la ciencia. Por la difusión del saber [...]. Pero la misión primaria, la que le otorga a un periodista ese nombre y no el de mediador, o de repetidor o monitor de ciencias, es la de dedicarse al funcionamiento de la ciencia, de relatarla. Y esto sólo puede hacerlo cuando se libere de la mirada del científico..."

\section{Juegos y apuestas de actores}

¿Imaginamos a periodistas judiciales controlados por jueces, a periodistas políticos amonestados por jefes de partidos y a periodistas deportivos regañando a reporteros por haber narrado mal (desde su punta de vista) una competencia? Pude constatar con cierto número de mis colegas que nuestros científicos se sienten tentados a veces a utilizar el argumento de la dificultad de las nociones científicas para limitar a los periodistas a la única función de explicación, de vulgarización correcta, bajo control. ¿Creen que caricaturizo? Cierto número de documentos, de comités, en estos últimos años, en Francia, han propuesto la creación de comisiones de control de la prensa en materia de temas científicos. El más reciente, el informe Kourilsky/Viney (informe al Primer ministro sobre el principio de precaución) aconseja y propone la creación en esos campos de una especie de Consejo del Orden de la prensa. Lejos de mí creer que el mundo de la prensa sería un paraíso para la circulación de las ideas. Intereses financieros, industriales, juegos personales, ambiciones, cacería de primicias, pereza intelectual reinan en las empresas de prensa como en todas las otras actividades humanas. Pero si los periodistas deben "criticar" a los científicos, ¿quién debe vigilar a los periodistas? Esta caricatura de pensamiento sería un error.

\section{Juegos y apuestas cientificistas}

¿Desearían los científicos que aceptáramos la idea según la cual ellos detentan un saber tan precioso que son los únicos que saben juzgar la calidad de su difusión en la sociedad? Los peligros de tal 
procedimiento de autocontrol saltan a la vista. Si, por ejemplo, la genética es demasiado compleja y misteriosa como para ser explicada en detalles, bastaría a los reporteros con ir a repetir que en los laboratorios se hace el trabajo... Y relatar (sin error) el número de secuencias genéticas cartografiadas para decir que los transgénicos no representan ninguna amenaza para la sociedad... Seamos serios, el oficio primero de un periodista es producir información, ponerla en un formato útil para su público con la mínima alteración del contenido. ¿Qué significa esto? ¡Que una información no es sinónimo de algún saber científico! Más que el número de secuencias genéticas etiquetadas en un cromosoma, es mucho más útil para la sociedad estar en capacidad de hacerse una idea del contexto histórico, social, financiero, cultural del descubrimiento... ¿Quién dice qué? ¿Por qué? ¿Cómo? Tantas preguntas casi siempre de difícil respuesta, dolorosas para los investigadores, sobre todo cuando los periodistas intentan forzar las puertas cerradas de los comités secretos, de los peritajes a puerta cerrada o de los coloquios cerrados... Henos aquí en lo más apretado del nudo. El periodista, interlocutor regular de los científicos, ¿debe ser él mismo un científico, en el sentido de adherir a la causa de la ciencia, hablar en nombre de la ciencia?

La conclusión de este análisis podría hacerse tomando las figuras de una vulgarización en discusión permanente con las tecnociencias. Pero me parece que ella está resumida en la conclusión de Patrice Lannoy: "Ciencia sin conciencia es sólo la ruina del alma, decía Rabelais. Se estaría tentado a precisar: La ciencia sin crítica estaría sorda a su conciencia..." El periodismo crítico sigue siendo, estoy persuadido de ello, el mejor aliado de la ciencia".

\subsection{La vulgarización, práctica crítica del cientificismo}

O sea que la vulgarización puede entenderse como crítica de las tecno-ciencias. Pero ¿en la práctica? Los heraldos, los periodistas hacen mucho. Sin embargo, vamos a llevar nuestra reflexión hacia objetos particulares, los objetos populares-mediáticos. Estos objetos son construcciones culturales que plantean numerosas preguntas, de ida y de venida: sus condiciones de creación, los signos (¡los síntomas!) de los que ellos son portadores, las situaciones de 
recepción que establecen y las representaciones que construyen. Cuando están cargados de tecno-ciencias, ¿qué se puede decir? Numerosos objetos populares-mediáticos -y es ésta nuestra doble hipótesis- por una parte vale la pena transformarlos en objetos de investigación y, por otra parte, son operadores críticos del cientificismo en sus diferentes figuras. Nos contentaremos con una enumeración, porque, sin duda alguna, el corpus merece que se lo trabaje más y las consecuencias teóricas sobre las investigaciones en materia de vulgarización de las tecno-ciencias ${ }^{20} \mathrm{y}$ de las relaciones tecnociencias-sociedades están lejos de ser problematizadas. Tres ejemplos pertenecientes a tres campos de la creación: un cuadro, un vestido y una instalación.

\section{Un cuadro - 1937}

Un cuadro. ¿Conocido?, ¿desconocido? Sí, conocido y más que eso. Guernica. ¿Habrá que comentar esta obra? ¿No? Sí.

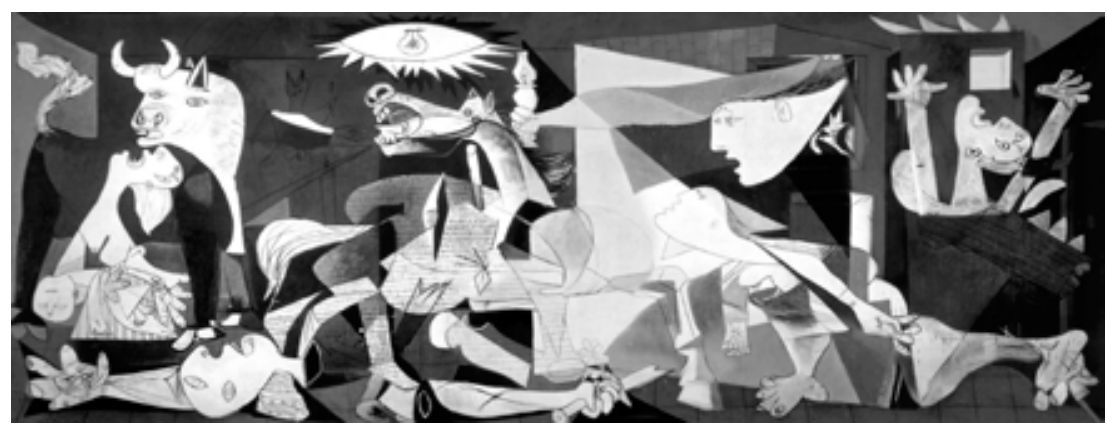

Imagen 1. Guernica, Pablo Picasso, 1937

Un detalle. A menudo no visto. Se trata de un problema de recepción. ¿Cómo ocurre que si uno retira la bombilla en su ojo-sol, el espectador ${ }^{21}$, que conoce la obra, no se percata de ello?

\footnotetext{
20 Claramente veremos que, en efecto, se trata de "techno-ciencias"...
}

21 Al trabajar la imagen con un programa de computador doméstico. 
La bombilla brilla por su ausencia en las representaciones que el público se hace del Guernica ${ }^{22}$. Esa bombilla es, sin embargo, la clave del problema. Si el público sabe que el cuadro fue concebido con ocasión de la Exposición Universal de 1937 para el pabellón de la República española, el público no sabe que el cuadro hacía parte de un encargo más general hecho a cuatro pintores: Fernand Léger, Raoul Dufy, Sonia Delaunay y Pablo Picasso. Se trata del tema central de la Exposición: "La electricidad al servicio de los hombres". En pleno Frente popular, pasamos lógicamente, si podemos decirlo así, del Hada Electricidad (Exposición Universal de 1900) a una electricidad cuyos beneficios deben revertirse en el bienestar de los Hombres. Y, de hecho, Fernand Léger pinta "A través de las montañas", un cuadro realista-socialista. La felicidad es la electricidad y los soviets. Es cierto que Raoul Dufy propone un Hada Electricidad, pero un hada producida por hombres (pocas mujeres): Edison y su bombilla, Ersted y sus imanes, Galvani y sus ranas, Volta y su pila, Marie Curie y su radium... En resumen, el conjunto de los hombres y las mujeres de ciencia que, directamente (o indirectamente, pero la pintura no lo dice) pusieron su saber al servicio de los hombres. Versión Frente popular del valor de la ciencia y del científico. ¿Al servicio de quién o de qué? Eso es precisamente lo que los cuadros de Sonia Delaunay muestran: variaciones sobre el papel que puede jugar la luz artificial para los pintores. La electricidad está realmente al servicio de los pintores. ¿Y Picasso? No se sabe. Él no dice nada de eso ${ }^{23}$. De todas maneras... esa bombilla situada en lugar de la pupila, en un ojo-sol cuyos rayos ya no tienen el aspecto difuso que tendrían cuando se mira al sol. Salen del sol como triángulos puntiagudos que se agrandan, que

22 En este momento, no buscamos construir un análisis cualquiera de las preguntas planteadas por esta ausencia. Simplemente, hicimos pruebas en las cuales presentamos a diferentes públicos (historiadores del arte, estudiantes de historia del arte, público mixto de comunistas, científicos, etc.) una imagen alterada: el ojo-sol-bombilla es remplazado por una mancha negra. El público sólo ve fuego...

${ }_{23}$ En todo caso, hasta el momento en que proponemos este texto al editor, no hemos encontrado ningún dato textual. 
cortarán los cuerpos de humanos o de animales. La bombilla-ojo-sol está exactamente en la posición del avión de las fuerzas franquistas cuando largó las bombas. La bombilla-ojo-sol desplaza y condensa el objeto tecno-científico mortífero -el avión y las bombas. Así, Picasso propone al público de la Exposición una metáfora para interrogarlo: ¿la electricidad, el avión, las tecno-ciencias al servicio de los hombres? Eso depende de quién oprima el botón, quién tenga la sartén por el mango, quién esté en los controles. El objeto mediático popular trabaja así una de las figuras del cientificismo que ya hemos encontrado y representa una primera práctica de crítica del cientificismo ${ }^{24}$.

\section{Un vestido - 1946}

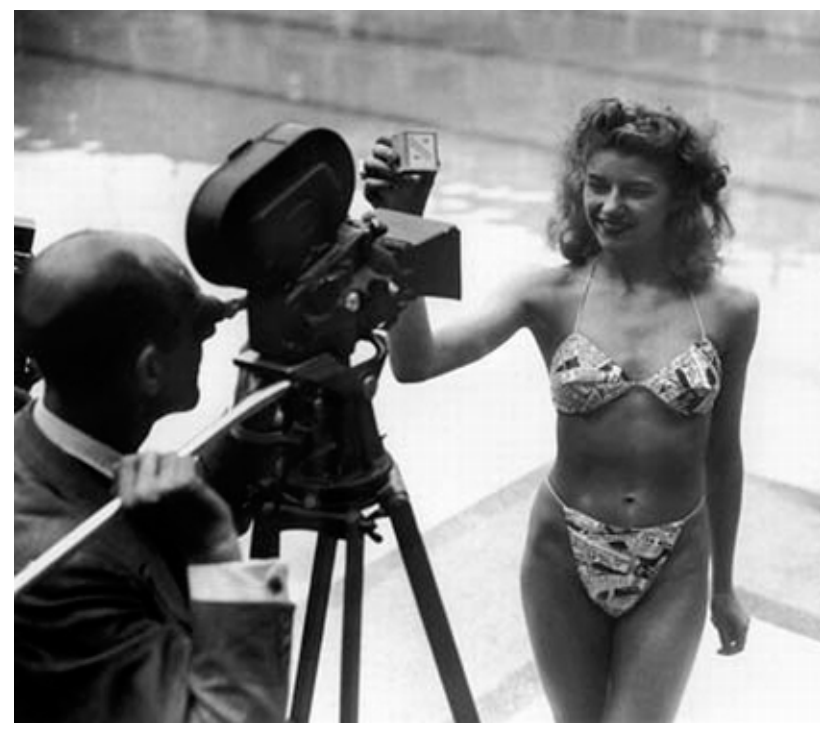

IMAGEN 2. BIKINI, EL INVENTO DEL DISEÑADOR LOUIS RÉARD, LANZADO EN 1946

24 A decir verdad, Picasso no es el único pintor que discutió sobre la ciencia en un plano filosófico mediante juegos metafóricos: Les Ambassadeurs de Holbein, La Nuit Étoilée de Van Gogh, Les Montres molles de Dalí, entre otros. 
Si la carpeta documental del segundo ejemplo es relativamente fácil de componer, su interpretación no lo es tanto. Tal parece que tiene que ver, otra vez, con el problema de la memoria social. Ese vestido es un trivial traje de baño. El ingeniero Louis Réard, al explotar las nuevas fibras en nylon y al mezclarlas con algodón permitió, a las mujeres, por fin, cambiar de look en las playas. En los años 1930, había sido producido un primer traje de baño de dos piezas, respondía al bonito nombre de Átomo. Louis Réard, por su parte, desdobla aún más los átomos, (como él mismo lo reivindica), reduce la materia y debe presentar un desfile en la piscina Molitor en París a comienzos de julio de 1936. Si le es difícil encontrar una modelo para lucir el traje -será una bailarina del Casino de París-, tampoco le fue fácil encontrarle un nombre: ¡Átomo ya había sido tomado! La actualidad le sirve de inspiración. Los norteamericanos hacen explotar la primera bomba atómica en tiempo de paz a finales de junio en uno de los atolones de las Islas Marshall, el atolón de Bikini. Descarga emocional en las neuronas de Louis Réard: los norteamericanos hicieron explotar una bomba atómica, él hará explotar una bomba anatómica. Inversión bajo la forma de juego de palabras: los norteamericanos habían llamado a sus bombas Little Boy y Granpa, Réard llama a la suya: ¡Bikini! Bomba sexual, sex-appeal (atómico).

¿Dónde están los hombres? ¿Dónde están las tecno-ciencias? Si la construcción del humor reardiano casi no plantea problemas, ¿qué nos quiere decir? ¿Que el mundo haría mejor con exponer en las playas otros objetos tecno-científicos? La crítica de nuevo se enfoca en las aplicaciones de la ciencia y en la decisión de producir tal o cual objeto tecno-científico. Sin embargo, otra vez el público obnubilado, en esta ocasión por las formas, no puede ver la distancia crítica asociada, ni el taparrabo, ni la "palabra justa" 25.

25 Para ser casi completos con respecto a este tema, señalemos también la nueva adaptación del éxito de los años 1940: Ah t'as qua ra boum dié..., que se convertirá, bajo la batuta de Jacques Hélian, en 1946: Ah la danse atomique! También hay una canción que se llama Bikini. 


\section{Dos instalaciones - 2000}

Los años 2000 vieron la explosión de las instalaciones artísticas sobre el $\mathrm{ADN}^{26}$. Las obras sobre el material genético fundamental son hoy tan numerosas que algunas han sido clasificadas bajo la rúbrica Arte transgénico ${ }^{27}$. Dos instalaciones pueden retener la atención. La primera es, claro está, el conejo fluorescente de Eduardo Kac, iniciador de ese arte. Sobre este conejo se ha escrito mucho. Recordemos que se trata simplemente de un conejo vuelto fluorescente gracias a un gen de medusa. Los comentarios al respecto han hecho carrera. Ante todo, los del mismo Eduardo Kac, en dos versiones:

- Hay quienes consideran que este arte nuevo se resume en una producción de obras en la encrucijada de tres culturas: la ciencia, el arte, las nuevas tecnologías ${ }^{28}$;

- Hay otros que interpretan ese arte como una forma de "hacer entrar en debate una red de interacciones sociales" ${ }^{29}$.

El mismo Eduardo Kac reivindica, para esta parte de su arte, el debate continuo entre profesionales de varias disciplinas (arte, ciencias, filosofía, derecho, comunicaciones, literatura, ciencias sociales) y el público, respecto a las implicaciones culturales y éticas de la ingeniería genética ${ }^{30}$. En este punto, lo que aparece claro es el objeto del debate: la función de la obra de arte. Se trata entonces

26 Citemos por placer una expresión del genetista alemán en un número ya antiguo de la revista Les Temps modernes: Genetics after Auschwitz, Holocaust and Genocide Studies 2, 3-20 (1987). French translation: Les Temps Modernes 511, 52 (1989).

${ }_{27}$ Ver, en la materia, un recorrido de las obras y de las reflexiones sobre esas obras en: POISSANT L. et DAUBNER E. (dirs.) (2005), Art et Biotechnologies, Presses de l'Université du Québec/Presses de l'Université de St Etienne.

28 REICHLE I. (2005), «Au confluent de l'art et de la science: le génie génétique en art contemporain». Ibíd., p. 260.

29 RIUSSÉ-LEMARIÉ I. (2005), «L'œuvre d'art et le vivant à l'ère des biotechnologies: entre médiation scientifique et artistique, mise en débat et catharsis». Ibid., p. 269.

30 KAC E. (2005), “GPF Bunny”, Ibíd, p. 158. 
de un debate que va más allá de los conocimientos. Aparece clara la función de la obra: desencadenar un debate. De nuevo se trata de cuestionar las aplicaciones de la ciencia, pero también entran en juego los interrogantes filosóficos y éticos (animalidad, producción de "quimeras"). Retorno al pasado, si evocamos las palabras de François de Neufchâteau: "La idea de una Exposición pública anual sobre los productos industriales" ${ }^{31}$.

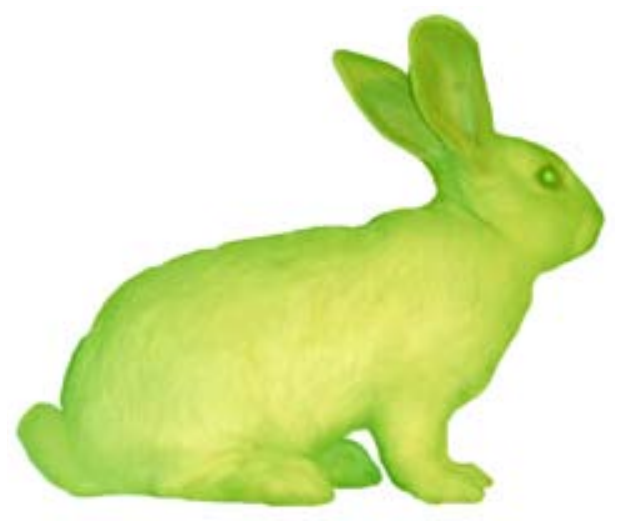

IMAGEN 3. GPF BUNNY, ALBA, LA CONEJITA FLUORESCENTE DEL ARTISTA BRASILERO EDUARDO KAC, 2000

La segunda instalación se titula, precisamente, Dialog with DNA. Es la obra de una artista japonesa, la señora Chiharu Shiota. Fue presentada en el Centro Cultural Japonés de Cracovia en 2002. Los habitantes de Cracovia debían ofrecer zapatos usados de su propiedad y que estuvieran cargados de recuerdos. Esos recuerdos debían figurar en pequeñas notas situadas al pie (isic!) de los zapatos. Estos últimos serían entonces testigos de la vida de su propietario ${ }^{32}$. Los zapatos, puestos en el suelo, están unidos entre ellos por una urdimbre de filamentos rojos que representan

\footnotetext{
31 Ver más arriba.

32 Uno no presta gustoso sus zapatos, pero un saco sí.
} 
los filamentos de la doble hélice. Esos hilos se unen en un punto Omega. En suma, todos somos diferentes, pero todos somos parientes gracias al conjunto de las moléculas de ADN que nos componen. Chiharu Shiota nos propone una discusión sobre el ADN y, de modo más amplio, sobre el lugar de la ciencia y de una teoría científica en nuestra vida. Debemos componer con todo y al mismo tiempo conservar nuestro "nosotros".

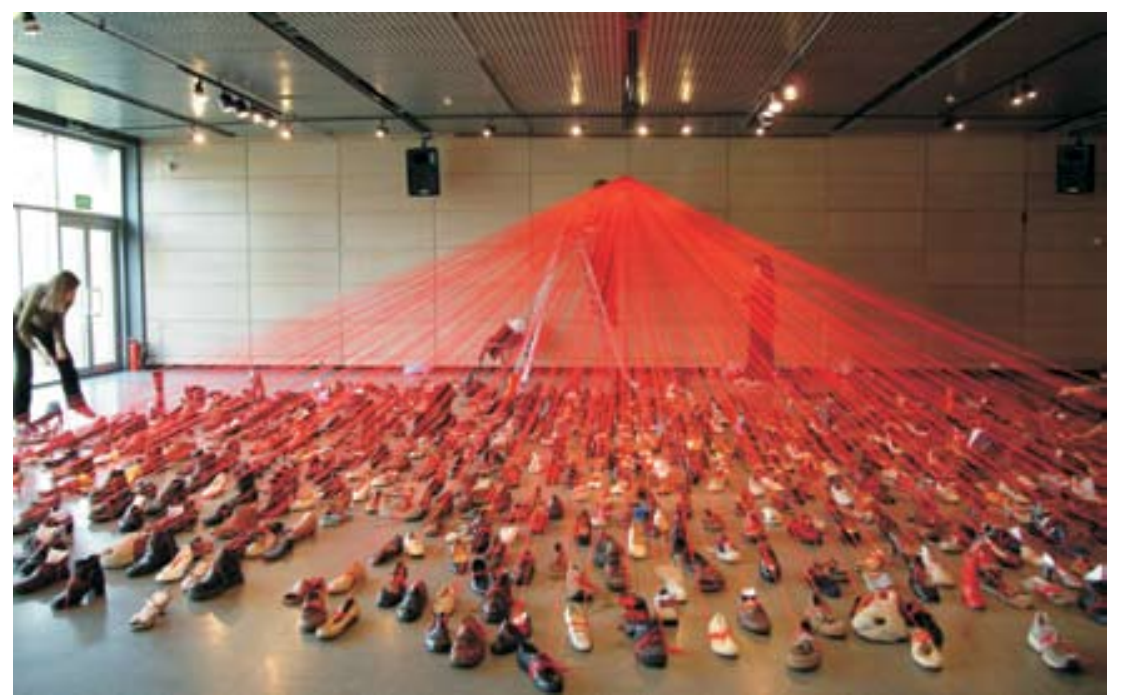

IMAgen 4. INSTALACIÓN "DIÁlOgO CON EL ADN", OBRA DE ARTISTA JAPONESA CHIHARU SHIOTA, PRESENTADA EN EL CENTRO CULTURAL JAPONÉS DE CRACOVIA, EN 2002

Cracovia está situada a 100 kilómetros de Auschwitz, donde se puede visitar otra "instalación" de zapatos cuyos propietarios no tuvieron tiempo de redactar sus relatos personales. Otra teoría científica había tenido otras consecuencias. 


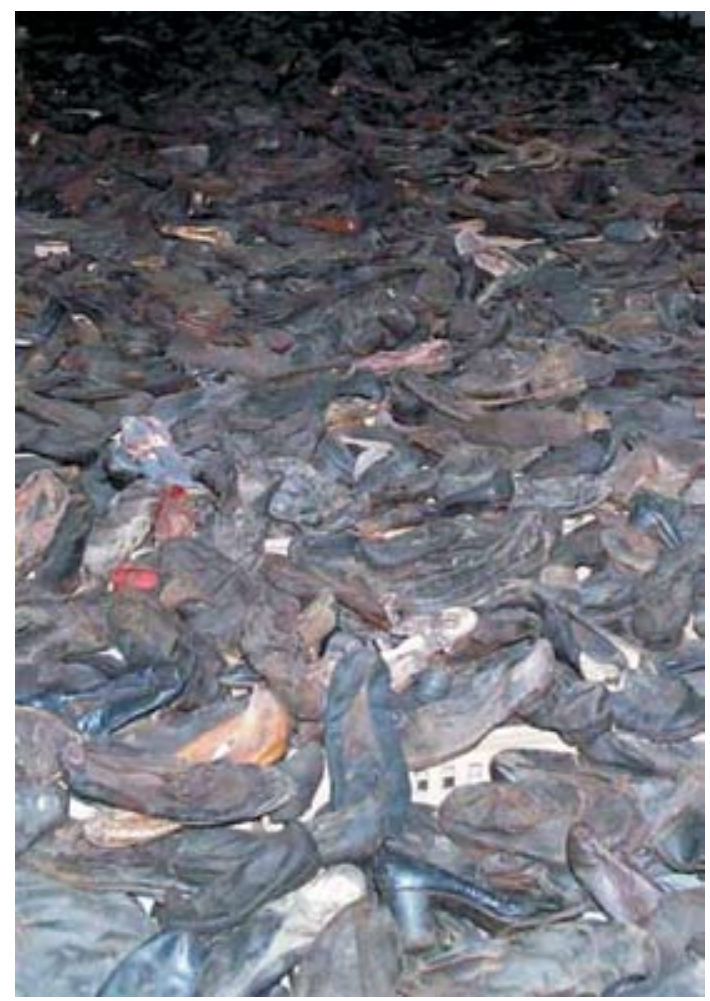

ImAgen 5. MILES DE ZAPATOS DE PRESOS ASESINADOS, CONSERVADOS EN EL MEMORIAL AND MUSEUM AUSCHWITZ-BIRKENAU

Digamos, finalmente, que el hecho de poner en debate mediante las instalaciones -la del conejo y la de los zapatos-introduce en el público y en la sociedad la discusión acerca de las implicaciones técnicas, filosóficas, culturales, éticas... de la ciencia, mucho más que el problema de los conocimientos.

Se podría intentar una síntesis si dirigimos nuestra mirada hacia los años 1955-1956. Sin entrar en los detalles de cada uno de los objetos mediáticos-populares, he aquí una lista no exhaustiva de acontecimientos marcados por algunos de esos objetos o por hechos que han producido ese tipo de objetos: 
- 1955: Movimiento Pugwash en torno a Einstein contra el desarrollo del arma atómica (y, por otra parte, muerte de Einstein).

- 1955: La Java des bombes atomiques, de Boris Vian.

- 1955: Traslado del Comisariado de Energía Atómica.

- 1955: Producción de la Dodge La Femme, el automóvil más consumidor de gasolina jamás producido y presentación del Citroën DS 19 en el Salón del Automóvil (el carro que marcó el siglo XX, "el auto del siglo").

- 1956: L’petit atome, canción de Paul Brafford, investigador del CEA.

- 1956: Palma de Oro en el Festival de Cannes: Le Monde du Silence (Del comandante Cousteau y Louis Malle; segunda película en mostrarle al mundo imágenes a color del mundo submarino y la primera en mostrar imágenes grabadas a 75 $\mathrm{m}$ de profundidad).

Esta lista permite plantear una vez más la pregunta acerca de la recepción de esos objetos y de sus consecuencias en la representación social de las tecno-ciencias. La colisión entre Le Monde du Silence y La Java des bombes atomiques es, a este respecto, muy reveladora. Subyace en ambos una concepción de la Naturaleza y de la intervención del hombre en la Naturaleza. Le Monde du Silence recibe la Palma de Oro, pero la canción de Boris Vian es manifiestamente poco conocida y poco apreciada ${ }^{33}$. Algunos años más tarde, la mayoría de los franceses aplaudirá la primera explosión atómica de Regane en Argelia (ifrancesa!). Las cosas cambiarán con el primer choque petrolero y los movimientos ecologistas en contra de las centrales nucleares. El público puede, al mismo tiempo, comprar una DS 19 (cuando no una Dodge La Femme) y aplaudir Le Monde du Silence que no padece todavía el

33 Il faut bien avouer que, avec sa chanson Le Déserteur, Boris Vian ne se fait pas que des amis! 
calentamiento climático y el efecto invernadero producido por los gases de los tubos de escape...

Los objetos mediáticos-populares responden bien a las ideas desarrolladas por los defensores de una vulgarización de las ciencias armada esencialmente de datos, de conocimientos científicos. Juegos metafóricos, desplazamientos en el lenguaje, risas, lágrimas y emoción componen una interrogación crítica sobre el lugar de las tecno-ciencias en la sociedad: aplicaciones de la ciencia, selección de los programas científicos, función y situación del científico en la sociedad, pero también relaciones entre teoría científica y lo humano.

Sin embargo, sin necesidad de evaluaciones, sin duda, hay un camino de la teoría a la práctica de la crítica del cientificismo. La idea de crítica se alía también con la idea de un discurso segundo, de un discurso tercero..., en resumen, de un discurso sin fin: más Wonderful que la pila Wonder, el discurso sobre las tecno-ciencias debería aumentar sin cesar cuando se lo utiliza, parafraseando a Barbara Cassin: "Más wonderful que la pila Wonder, no solamente el discurso no se usa cuando uno se sirve de él, sino que él aumenta" ${ }^{34}$.

Por una parte, la reacción del público es escasa. Por otra parte, de forma manifiesta, son numerosos quienes tienen dificultad en aceptar que la ciencia pueda tener un lugar "normal" en la sociedad. A partir de ahí podemos oírlos cuando contestan el hecho de que esos objetos mediáticos-populares sean objetos de vulgarización de las ciencias, puesto que ellos no transportan hacia el gran público conocimientos en cantidad suficiente... y entonces volvemos a la interrogación del comienzo: ¿Qué es, pues, la vulgarización de las ciencias? Cientificismo, ¿hasta dónde nos sujetas?

34 Cassin B. (1990). Le lien rhétorique. In Philosophie, 28. 